\title{
Artificial Intelligence-Aided Precision Medicine for COVID-19: Strategic Areas of Research and Development
}

Enrico Santus ${ }^{1,2}$, PhD; Nicola Marino ${ }^{2,3}$, BSc; Davide Cirillo ${ }^{2,4}, \mathrm{PhD} ;$ Emmanuele Chersoni ${ }^{5}$, PhD; Arnau Montagud ${ }^{4}$, $\mathrm{PhD}$; Antonella Santuccione Chadha ${ }^{2,6}, \mathrm{MD}$; Alfonso Valencia ${ }^{4,7}, \mathrm{PhD}$; Kevin Hughes ${ }^{8}, \mathrm{MD}$; Charlotta Lindvall ${ }^{9,10}$, $\mathrm{MD}, \mathrm{PhD}$

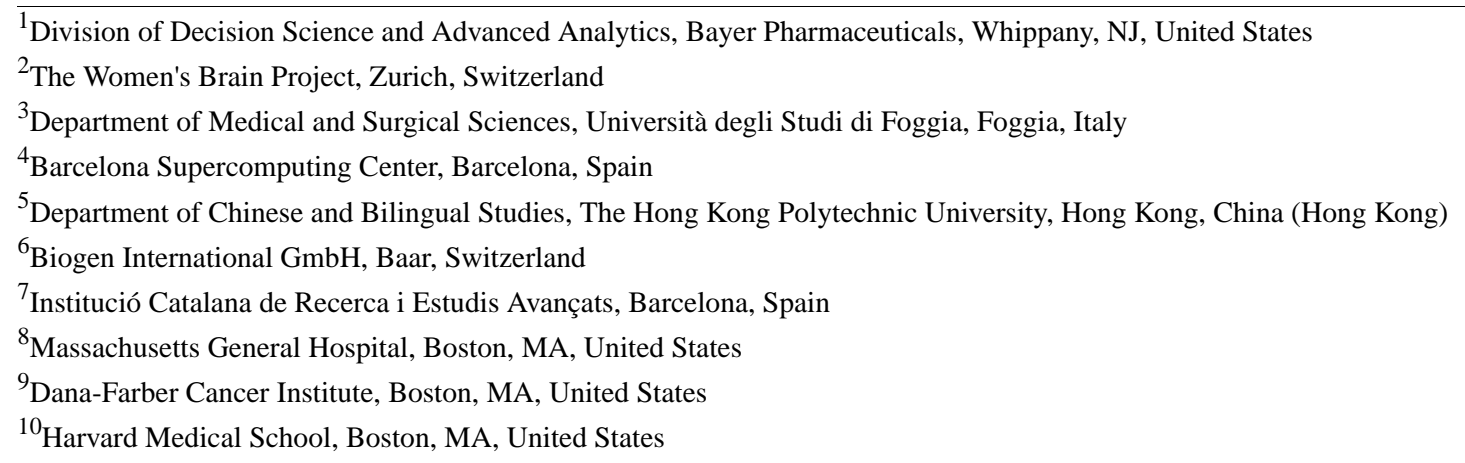

Corresponding Author:

Davide Cirillo, PhD

Barcelona Supercomputing Center

c/Jordi Girona, 29

Barcelona

Spain

Phone: 34934137971

Email: davide.cirillo@bsc.es

\section{Abstract}

Artificial intelligence (AI) technologies can play a key role in preventing, detecting, and monitoring epidemics. In this paper, we provide an overview of the recently published literature on the COVID-19 pandemic in four strategic areas: (1) triage, diagnosis, and risk prediction; (2) drug repurposing and development; (3) pharmacogenomics and vaccines; and (4) mining of the medical literature. We highlight how AI-powered health care can enable public health systems to efficiently handle future outbreaks and improve patient outcomes.

(J Med Internet Res 2021;23(3):e22453) doi: 10.2196/22453

\section{KEYWORDS}

COVID-19; SARS-CoV-2; artificial intelligence; personalized medicine; precision medicine; prevention; monitoring; epidemic; literature; public health; pandemic

\section{Introduction}

The ongoing COVID-19 pandemic has highlighted the fragility of the health care system during unexpected events, testing the endurance of even the top-performing ones [1]. As noted by several scholars, embracing artificial intelligence (AI) for health care optimization and outcome improvement is not an option anymore [2]. Concerning the ongoing COVID-19 pandemic, several studies have highlighted that the timely inclusion of AI-powered technologies would have accelerated the identification of and effective response to COVID-19 outbreaks worldwide. An example is the widely reported algorithm from the Canadian company BlueDot, based on natural language processing (NLP) and machine learning, which forecasted the emerging risk of a virus spread in Hubei province in late December 2019, by screening news reports and airline ticketing [3].

Awareness of the benefits of employing AI to support and manage the COVID-19 crisis and its aftermath is increasing, particularly in the medical and research community. Notable examples of early AI-powered contributions include the discovery of relevant SARS-CoV-2 target proteins by 
DeepMind's AlphaFold [4] and the design by Infervision of a computer vision algorithm for the detection of coronavirus pneumonia based on lung images [5].

Benefits do, however, come with technical challenges and related risks that still need to be properly assessed. For example, the absence of transparency and interpretability in AI models obscures the fact that the efficacy of these technologies is not equal across population groups. COVID-19 incidence and outcomes vary according to a large number of individual factors, including age, sex, ethnicity, health status, drug utilization, and others [6]. Sensitizing AI technologies to the diversity of the patient population and ensuring data security [7] is imperative to avoid biased decisions [8-10]. Therefore, a crucial step to obtain robust, trustworthy, and intelligible applications that account for demographic equity is to assess potential biases in the resources used to train AI models for precision medicine [11].

As of today, AI systems are, regrettably, rarely endowed with robustness to class imbalances, such as sex and gender groups [12]. In this regard, sex differences in COVID-19 cases, as well as sex-specific risk factors and socioeconomic burden, have been recently highlighted in a case study by the European Commission [13]. Dataset multidimensionality that can fairly represent the population constitutes one of the main challenges for biobanking and cohort design efforts that collect different axes of health data [14]. In this regard, fair and broad data collection systems are of primary importance. Two essential international references for COVID-19 genomic and medical data are the EMBL-EBI COVID-19 Data Portal [15] and the NIH National COVID Cohort Collaborative (N3C) [16]. The COVID-19 Host Genetics Initiative [17] is an international collaborative undertaking to share resources to investigate the genetic determinants of COVID-19 susceptibility, severity, and outcomes [18]. The Coronavirus Pandemic Epidemiology (COPE) consortium aims to involve experts in the development of a personalized COVID-19 Symptom Tracker mobile app that works as a real-time data capture platform [6], which garnered over 2.8 million users in a few days. Moreover, COVID-19 sex-disaggregated data are collected by Global Health $50 / 50$ [19], an initiative housed at University College London, advocating for gender equity.

Other ethical concerns include life-or-death decisions through risk prediction models, which may help optimize resource allocation in times of scarcity. The application of nonoptimal models may incur the risk of worsening biases and exacerbating disparities for people with serious illnesses and different treatment priorities, potentially causing the reduction in the use of services rather than achieving the best patient care [20]. Nevertheless, the power of prediction models is impressive, and it may play a key role in the future if properly exploited. For instance, a study from Cambridge University [21] shows how the use of secure AI operating on anonymized COVID-19 data can accurately predict the patient journey, allowing an optimal allocation of resources and enabling well-informed and personalized health care decision-making. This is a particularly important point, especially considering the difficulty in managing the increasing need for intensive care units (ICUs) during the COVID-19 pandemic peak [22,23].
The way the AI systems will be exploited is probably the most delicate topic in this adoption process, particularly if we refer to the decisional independence of the medical staff. As humans, in fact, clinicians are also affected by numerous cognitive biases, including the confirmation bias, which may lead them to give excessive importance to the evidence supporting automated prediction (eg, risk prediction, diagnosis, and treatment suggestion) and ignore evidence that refutes it [8,24].

Despite the abovementioned concerns, there are numerous success stories in the adoption of risk prediction models. For example, Duke University adopted a system called Sepsis Watch that identifies in advance the inflammation leading to sepsis-one of the leading causes of hospital deaths. Within two years from the tool introduction, the number of sepsis-induced patients drastically decreased [25], thanks to three key elements: (1) adaptation of the predictive model to a highly specific context; (2) scalability through integration with hospital workflows; and (3) the adopted user experience-based approach, which places clinicians and health care professionals at the center of the software development process, adhering with the human-in-the-loop paradigm [26,27].

The COVID-19 crisis is accelerating anticipated changes towards a stronger collaboration between computer science and medicine. In particular, the crisis has exposed the need for increased scrutiny of the relationship between AI and patients as well as health care personnel under the lens of human and emotional needs, as demonstrated by the surge of mental health consequences of the pandemic [28] and the growing development of AI-based mental health apps and related digital tools [29]. Such aspects, together with others related to general data access and the use of AI for disease outcome prediction, are fueling the current debate about the convergence of AI and medicine $[30,31]$ and the actionable realization of AI-powered innovations to bridge the gap between technological research and medical practice, including applications in medical triage and advice, diagnostics and risk-adjusted paneling, population health management, and digital devices integration [32]. Concerning this aspect, it is important to mention the recent publication of guidelines for the rigorous and transparent adoption of $\mathrm{AI}$ in the clinical practice: CONSORT-AI (Consolidated Standards of Reporting Trials-Artificial Intelligence) [33] and SPIRIT-AI (Standard Protocol Items: Recommendations for Interventional Trials-Artificial Intelligence) [34].

Translating patient data to successful therapies is the major objective of implementing AI for health [35], especially in times of a pandemic crisis, with the ultimate goal of achieving a successful bench-to-bedside model for better clinical decision-making [36,37]. In this work, we review some major examples of what AI has achieved during the COVID-19 pandemic and the challenges that this technology and the medical community are currently facing in four main strategic areas of research and development (Figure 1): (1) triage, diagnosis, and risk prediction; (2) drug repurposing and development; (3) pharmacogenomics and vaccines; (4) mining of the medical literature. 
Figure 1. Main strategic areas of research and development for the realization of artificial intelligence (AI) to fight COVID-19: (1) triage, diagnosis, and risk prediction; (2) drug repurposing and development; (3) pharmacogenomics and vaccines; and (4) mining of the medical literature. The text within the four panels enlists the advantages and actionable solutions exhibited by the AI-aided precision medicine approaches surveyed in this work.

\section{TRIAGE, DIAGNOSIS, RISK PREDICTION}

- Treatment priorities for optimal resource allocation - Patient management and patient trajectory

- Risk of mortality and disease severity

- Validation and benchmarking standards

Unstructured information processing

- Knowledge representation and learning

- Extraction of bio-entity relationships

- Open accessibility and automated updates

MINING OF THE MEDICAL LITERATURE

\section{DRUG REPURPOSING AND DEVELOPMENT}

- Long-term and cost-effective solutions

- Insights into virus-host interactions

- Accelerated drug discovery pipelines

- Drug engineering and novel compounds
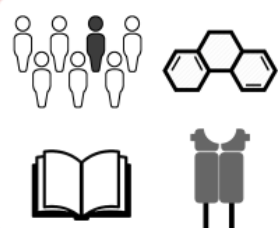

$\prod$

- Personalized clinical decision support

Actionable genetic markers

- Infection susceptibility and severity

- Identification of potential epitopes

PHARMACOGENOMICS AND VACCINES

\section{Triage, Diagnosis, and Risk Prediction}

AI has been applied to determine treatment priorities in patients with COVID-19 or triage and to better allocate limited resources. A group of researchers at the General Hospital of the People's Liberation Army (PLAGH), Beijing, China, has developed an online triage tool model [38] to manage suspected COVID-19 pneumonia in adult patients with fever [39]. Using clinical symptoms, routine laboratory tests, and other clinical information available at admission (eg, clinical features), they trained a model based on logistic regression with the least absolute shrinkage and selection operator (LASSO), obtaining an area under the receiver operating characteristic curve (AUROC) of 0.841 (100\% sensitivity and $72.7 \%$ specificity). Based on data from two hospitals in Wenzhou, Zhejiang, China, another study group recently used an entropy-based feature selection approach: they modeled combinations of clinical features that could identify initial presentation patients who are at a higher risk of developing severe illness, with an accuracy of $80 \%$ [40]. Their results show that mildly elevated alanine aminotransferase levels, the presence of myalgias (body aches), and an elevated hemoglobin level (red blood cells), in this order, are predictive of the later development of acute respiratory distress syndrome.

A thorough study on risk prediction was carried out at the University of Cambridge based on the development of a proof of concept system to model the full patient journey through risk prediction models [21]. By identifying the risk of mortality and ICU/ventilator need, the system aims at enabling doctors to answer questions such as: Which patients are most likely to need ventilators within a week? How many free ICU beds in the hospital are we likely to have in a week from now? Which of two patients will get more benefits from going on a ventilator today? The predictive models showed accuracies ranging from $77 \%$ for ventilator need to $83 \%$ for ICU admission and $87 \%$ for mortality.

Risk prediction models are not new to the AI-aided health care approach. They have already been successfully utilized for tasks such as predicting the risk of developing cancer [41,42] and identifying which patients are likely to benefit from heart-related procedures [43]. However, the COVID-19 crisis has accelerated the utilization of such models. In a recent study, Wynants and collaborators [44] screened 14,217 published titles about the pandemic from PubMed and Embase (Ovid, arXiv, medRxiv, and bioRxiv), finding over 107 studies describing 145 prediction models. Among them, 4 models aimed to identify people at risk and 50 , to predict the mortality risk, progression to severe disease, ICU admission, ventilation, intubation, or length of hospital stay. These models not only provide interesting results but also inform about the most valuable predictors, such as age, body temperature, lymphocyte count, and lung imaging features. Despite this, these models cannot be directly applied in the clinical setting without further validation, in order to guarantee data and experiment transparency and robustness, together with decision interpretability and model generalizability.

The remaining 91 models from this study were dedicated to the diagnosis of COVID-19, 60 of which exploited medical imaging. This number clearly shows that diagnosis is another important field for the application of AI techniques [45], with digital pathology exhibiting high effectiveness. In particular, convolutional neural networks (CNNs) have been supporting radiologists in their expert decisions [46]. In a recent study, a CNN was trained to automatically learn patterns related to COVID-19 (ie, ground-glass opacities, multifocal patchy 
consolidation, and/or interstitial changes with a predominantly peripheral distribution), achieving an AUROC of 0.996 (98.2\% sensitivity and $92.2 \%$ specificity) and outperforming the reverse-transcription polymerase chain reaction, which also suffers from a significant time lag. In addition to accuracy, these approaches put the speed of the diagnosis on the table: CNNs can analyze up to 500 images in a few seconds, whereas radiologists would need hours to complete the same task.

Although chest computed tomography (CT) scans represent a commonly exploited source of information to train AI to rule out SARS-CoV-2 infection, the rapid detection of patients with COVID-19 can greatly benefit from learning approaches that utilize heterogeneous types of data. In this regard, it is crucial to consider the importance of training CNNs in a correct gender balance in medical imaging datasets to avoid producing distorted classifications for assisted diagnosis [12]. Moreover, it is crucial to rely on high-quality benchmarking and robust validation strategies to assess the generalization of the model to other datasets and populations $[47,48]$.

Indeed, AI can exploit multidimensional data, including the series of epidemiological, clinical, biological, and radiological criteria defined by the World Health Organization [49]. In a collaboration between researchers at hospitals in China and in the USA, CNN and other machine learning methods (eg, support vector machine, random forest, and neural networks) have been used to model and integrate CT scans and clinical information for diagnostic purposes [45]. The joint model that uses both information sources achieved a 0.92 AUROC $(84.3 \%$ sensitivity and $82.8 \%$ specificity), outperforming the individual models. Moreover, the models allowed the identification of age, viral exposure, fever, cough, cough with sputum, and white blood cell counts as the main features associated with SARS-CoV-2 infection status.

Recently, the National Institute of Biomedical Imaging and Bioengineering has launched the Medical Imaging and Data Resource Center with the goal of coupling AI and medical imaging for COVID-19 early detection and personalized therapies [50].

AI has also been utilized to identify patients at higher risk of mortality. Researchers at the Tongji Hospital, Wuhan, China, have screened electronic health records of 375 discharged patients to use clinical measurements as features and have trained a gradient-boosted decision tree model to predict mortality risk [51]. The accuracy of the system was 93\%. Its utilization would make it possible for physicians to immediately identify critical cases and act accordingly. The model was also able to detect three key clinical features, that is, lactic dehydrogenase, lymphocyte count, and high-sensitivity C-reactive protein.

\section{Drug Repurposing and Development}

Although triage, diagnosis, and risk prediction are three of the most relevant tasks that AI has helped with during the peaks of the pandemic, other objectives are currently being addressed for long-term solutions. Among them are target selection for

drug repurposing [52] and approaches for drug development, including de novo drug design [53].

Drug repurposing comprises identifying existing drugs that could effectively act on proteins targeted by the virus. Recently, 332 high-confidence SARS-CoV-2 protein-human protein interactions have been experimentally identified, as well as 69 ligands, comprising drugs approved by the US Food and Drug Administration (FDA) and compounds in preclinical and clinical trials, which specifically target these interactions [54]. Understanding which proteins and pathways in the host the virus targets during infection is crucial for the development of AI systems for drug repurposing.

For instance, algorithms modeling the interaction between drugs and proteins have helped identify baricitinib, which was previously used for the treatment of arthritis, as a useful drug against COVID-19 [55]. This drug inhibits the proteins that help the virus penetrate the host cell. Thanks to approaches that exploit the computational identification of relations between existing drugs and target molecules, research published by a team of Korean and American scientists has allowed the identification of FDA-approved antivirals that could potentially target the key proteins for COVID-19 [56].

The molecular processes of virus-host interactions have been recently reconstructed in an international effort coordinated by domain experts, called the COVID-19 Disease Map project [57]. The project aims to maintain an open-access resource for continuous, curated integration of data and knowledge bases to support computational analysis and disease modeling. It represents a milestone of paramount importance for the development of AI systems for SARS-CoV-2 and their comparison with models of other coronaviruses. Moreover, by providing information about the intermolecular wiring of virus-host interactions, the project enables network-based AI modeling for COVID-19 drug repurposing, which has recently shown promising results by using network diffusion and network proximity [58]. Moreover, deep neural networks largely employed in NLP, such as the Transformer architecture, have also been proposed for COVID-19 drug repurposing [56].

In the field of drug development, that is, the pharmacotherapeutic course of a newly identified lead compound, computational models have been proven extremely successful in facilitating a quicker, cheaper, and more effective development of new drugs [59]. For instance, AI can map multidimensional characteristics of proteins to considerably speed up the research process in comparison to traditional methodologies such as x-ray crystallography. In this regard, AI is crucial in optimizing drug discovery pipelines and improving drug development outcomes, with estimated costs of US \$2.6 billion [59].

Structural modeling and chemoinformatics methods for COVID-19 (eg, docking-based binding conformation studies of small molecules to target human or viral proteins) can greatly benefit from AI solutions. For instance, AI-based approaches have been used to infer structural similarities among molecules, such as algorithms that can model the graphical structure of chemical compounds through graph convolutional networks or other approaches [60]. AI systems can also leverage knowledge 
about protein sequences to infer the activity of similar ones. As previously mentioned, Google DeepMind has managed to predict the structure of five proteins targeted by SARS-CoV-2, namely SARS-CoV-2 membrane protein, Nsp2, Nsp4, Nsp6, and papain-like proteinase (C-terminal domain) [4]. The deep learning approach uses amino acid features from similar sequences, based on multiple sequence alignment, to infer the distribution of structural distances to predict the protein structures [61].

Finally, AI can also be used to synthetically generate new molecules, such as new chemical compounds. For instance, the biotech company Insilico Medicine used reinforcement learning to model small molecules and identify those that inhibit specific infection pathways. The team created a generative chemistry pipeline to design novel SARS-CoV-2 inhibitors to later be synthesized and tested. The pipeline employs a large array of generative models, including autoencoders, generative adversarial networks, and genetic algorithms optimized with reinforcement learning [53].

\section{Pharmacogenomics and Vaccines}

Pharmacogenomics, which is the study of the role of genomic characteristics of an individual in drug response, represents a key gateway to personalized medicine [62-64]. Although the translation of genomic information into clinical practice is recognized as one of the most challenging aspects of the future of medicine [65], the information about the genetic makeup of individual patients has the potential to guide clinical decision support and to facilitate biomedical research in many different areas. For instance, genomics can inform drug discovery by providing simultaneous insights into the disease mechanisms and potential targets for treating individual patients [66].

Pharmacogenomics approaches to COVID-19 are still in their infancy. Indeed, although the SARS-CoV-2 genome was published in draft on January 10, 2020 [67], and real-time tracking of the pathogen evolution is now available [68], much less genomic information is currently available about the host. Several studies focus on genetic variations associated with susceptibility to infection and clinical manifestations, including human leukocyte antigen (HLA) variants in the UK Biobank population-based cohort [69] and angiotensin-converting enzyme 2 (ACE2) variants in the Italian population [70]. Retrospective and prospective studies focusing on COVID-19 disease susceptibility and severity have been collected by the COVID-19 Host Genetics Initiative [17,18].

Despite the absence of direct evidence of pharmacogenomics data in COVID-19 patients, the related literature for COVID-19 therapies, including hydroxychloroquine, ribavirin, and baricitinib, has been recently surveyed [71]. Potential actionable genetic markers have been reported, namely, several genetic variants that can alter the pharmacokinetics of drugs that may affect the response to COVID-19 treatments. Importantly, as age, race, gender, and comorbidities have been associated with COVID-19 risk [72], these factors are deemed warranted to assess their role in the variation of treatment responses and need further investigation.
Population genetics is also needed to better understand the association between genetic variability and COVID-19. The importance and complexity of population genetic information, such as genome-wide association studies (GWAS), for drug discovery are exemplified by a study showing that $8 \%$ of drugs approved by the FDA target molecules with genetic support, whereas only $2 \%$ of phase- 1 drugs are genetically supported [73]. Despite such low rates, GWAS can help identify therapeutics that can be repurposed to treat individuals affected by diseases that are mechanistically related to those for which the drugs were developed [74]. Insights from GWAS can also inform about better patient management and therapy, such as the case of variants in six genes on chromosome 3 , namely SLC6A20, LZTFL1, CCR9, FYCO1, CXCR6, and XCR1, which have been recently associated with severe COVID-19 cases with respiratory failure [75].

Understanding population genetic heterogeneity is crucial for vaccine design, in particular, as it concerns the individual variability of the major histocompatibility complex (MHC-I and MHC-II) proteins, encoded by the HLA gene, which present SARS-CoV-2 epitopes to the immune system. Such individual variability, coupled with the importance of cellular immunity in the severity of the response to the infection, makes the identification of actionable targets for COVID-19 vaccines a challenging endeavor. AI models for COVID-19 vaccine development focus on the prediction of potential epitopes by using a variety of techniques, such as deep docking [76], long short-term memory networks [77], extreme gradient boosting [78], as well as approaches that account for different $H L A$ alleles by combining several existing machine learning tools [79]. A recent survey of AI-based approaches to COVID-19 vaccine design [80] suggests that the most popular candidate is the SARS-CoV-2 spike protein, which initiates the interaction with the host through the attachment to the ACE2 receptor [81].

\section{Mining of the Medical Literature}

The staggering rate of publications about COVID-19, both in the form of preprints and peer-reviewed articles, is posing unprecedented challenges to knowledge acquisition and the information quality assessment process. A large part of content is produced by humans for humans, in the form of free text, where crucial pieces of information end up being buried. Because free text is not intelligible by machines, human intervention must identify the relevant pieces of information from the publications and turn it into a tabular form. Recent developments in NLP techniques have helped the automation of this process through machine learning and, in particular, deep learning algorithms [82,83]. Symptoms, patient demographics, clinical data, algorithms, performance, and limitations are identifiable in the texts by properly trained models, which can obtain comparable accuracy to humans at a much faster rate, making it finally possible to monitor the enormous volume of the literature produced [84]. The resulting structured data can be exploited to enrich knowledge graphs (KGs) [85-87], which provide a means to represent and formalize information [85,88], analytical, relational, and inferential investigations and fill the knowledge gaps in the community. Moreover, to rationalize the immense quantity of information on COVID-19, new algorithms 
can generate low-dimensional representations of the KGs, allowing researchers for clustering and classification [85,89].
We list here representative $\mathrm{KG}$ efforts that have been directed at the fight against COVID-19 (see Textbox 1).

Textbox 1. Knowledge graph resources for COVID-19.

\author{
Project names and references: \\ - KG-Covid-19 Knowledge Graph Hub [90] \\ - COVID-19 Community Project [91] \\ - $\quad$ COVID-KG [92] \\ - CovidGraph [93] \\ - COVID-19 Miner [94] \\ - COVID-19 Biomedical Knowledge Miner [95] \\ - COVID-19 Taxila [96]
}

The KG-Covid-19 Knowledge Graph Hub project is the first Knowledge Graph Hub (KG-Hub) [90] dedicated to COVID-19. $\mathrm{KG}-\mathrm{Hub}$ is a software to download and transform data to a central location for building KGs from different combinations of data sources. The Covid-19 KG-Hub downloads and transforms data from more than 50 different COVID-19 databases of drugs, genes, proteins, ontologies, diseases, phenotypes, and publications and generates a KG that can be used for machine learning.

The COVID-19 Community Project [91] is a community-based KG that links heterogeneous datasets about COVID-19, in three main areas: the host, the virus, and the cellular environment. These KGs use several publicly available datasets, such as the CORD-19 dataset, a set of over 51,000 scholarly articles about coronaviruses [97].

Other notable databases used in KGs are the COVID-19 Data Portal (see Introduction) and The COVID-19 Drug and Gene Set Library [98]. One of the tools that use these is the COVID-KG [92], which embeds entities in the KG, such as papers, authors, or journals [99].

CovidGraph [93] is a collaboration of researchers to build a research and communication platform that encompasses over 40,000 publications, case statistics, genes and functions, molecular data, and much more. The output is a KG in which entity relationships can be found and new pieces of literature can be discovered. Another tool that uses the CORD-19 dataset is COVID-19 Miner [94], which provides access to a database of interactions among genes or proteins, chemicals, and biological processes related to SARS-CoV-2, which are automatically extracted using NLP from the CORD-19 dataset and manuscripts updated daily from the preprint servers medRxiv and bioRxiv [100].

Furthermore, COVID-19 Biomedical Knowledge Miner [85,95] is an intent to lay the foundation for a comprehensive and interactive $\mathrm{KG}$ in the context of COVID-19 that connects the causes and effects and enables users to completely explore the information contained therein. Data are supplied from papers available in PubMed and preprints available from platforms such as bioRxiv, chemRxiv, medRxiv, PrePrints, and Research Square. Lastly, COVID-19 Taxila [96] is an AI and NLP system that uses thousands of COVID-19-related publications, clinical trials, and other relevant sources to enable users to search and analyze the COVID-19 literature. Publications and data are automatically updated.

\section{Discussion}

The COVID-19 pandemic has caused some of the most significant challenges that national health care systems have had to face in recent human history. These systems include not only hospitals but also a multitude of clinicians, retirement and nursing homes, families, and communities. Government lockdown policies undertaken to reduce hospital strain has impacted the society as a whole and has also had social and economic consequences, which have been more severe for minorities and vulnerable groups [101]. Moreover, this pandemic is taking place in the age of social media and Web 2.0, which contain plenty of misinformation and fake news, and with no way for the average internet user to check the reliability of the sources. Nevertheless, the COVID-19 crisis has also shown the promise of technology in facilitating a better understanding of a complex disease and its impact on public health.

Here, we illustrated examples of how AI can advance research and clinical medicine and prepare governments for future similar crises. AI shows promise to deliver models for outbreak analytics and detection, prevention, early intervention, and decision-making. We highlighted the unparalleled opportunity for AI to fill the gap between translational research and clinical medicine. Finally, in addition to the medical applications of AI, it is worth mentioning the potential of NLP for monitoring the quality of the information available to the public and fighting fake news [102-104].

Thanks to the availability of big data and high-performance computing, the fight against the novel coronavirus can leverage the support of AI, as demonstrated by initiatives such as the COVID-19 High Performance Computing Consortium [105]. This technology allows us to address, at a much higher speed and a comparable performance, complex tasks that cannot be executed by humans-who can now focus on more intelligence-demanding activities such as emotional intelligence and human-to-human bonding [106]. 
Although AI is traditionally trained on large datasets for identifying population-level patterns (ie, common characteristics among people belonging to some clinical classes), recent efforts have promoted the utilization of this technology in conjunction with the principles of precision medicine, to substitute the "average patient" [42] with a real individual, based on geographical and socioeconomic signature as well as genetic, epigenetic, and other molecular profiles [107]. Under this paradigm, AI is meant to empower clinicians to tailor interventions [108] (whether preventive or therapeutic) to the nuanced - and often unique-features of every human being [109]. To this end, multidimensional datasets, such as the variety of data modalities that are currently collected and modeled for COVID-19 [110-112], capture individual genetic, biochemical, physiological, environmental, and behavioral variations [113] that may interfere with the development, progression, and treatment of a disease. Thanks to the drop in price of sequencing the human genome (from billions to hundreds of dollars in 30 years [114]), it is now possible to exploit AI to study phenotypic, genotypic, and environmental correlations among diseases [115].
With this approach, AI can predict the risk of an individual to develop a disease and estimate the likelihood of success for a treatment. In the case of COVID-19, this could lead to a better allocation of resources and an improved match between treatments and patients, consequently improving outcomes for preventive and therapeutic interventions. Therefore, AI-aided precision medicine connects some of the key benefits for a sustainable and effective health care system: efficiency, efficacy, and safety assessment [30].

$\mathrm{AI}$ is recognized as a necessity to achieve precision medicine in COVID-19. The current crisis has highlighted that a huge amount of work is still needed to exploit AI-based solutions to their full potential in order to transform health care. AI implementation in the clinical setting is still far from completion [115]. The highly fragmented and diverse health care systems, absence of a protocol for documenting patient data, ethical constraints (such as privacy), and limitations of AI itself (eg, bias and non-interpretability) still represent serious challenges to extensive AI adoption [116].

\section{Acknowledgments}

We are deeply thankful to the Women's Brain Project (WBP) (www.womensbrainproject.com), an international organization advocating for women's brain and mental health through scientific research, debate, and public engagement. The authors would like to thank Maria Teresa Ferretti and Shahnaz Radjy for the helpful comments. DC, AM, and AV have received funding from the European Commission's Horizon 2020 Program H2020-SC1-DTH-2018-1, "iPC-individualizedPaediatricCure” (ref. 826121), and H2020-ICT-2018-2, "INFORE-Interactive Extreme-Scale Analytics and Forecasting” (ref. 825070).

\section{Authors' Contributions}

ES and NM conceived the study with the contribution of ASC, EC, and DC. ES and NM directed the content selection and design, assisted by EC, DC, and AM. AV, KH, and CL supervised the project. The corresponding author had the final responsibility for the decision to submit the manuscript for publication. All authors have contributed to the writing and editing of the manuscript and have read and approved the final manuscript.

\section{Conflicts of Interest}

ASC and ES are currently employees at Biogen International GmbH, HQ, Switzerland, and Bayer Pharmaceuticals, USA, respectively. The other authors declare no competing interests. KH is a founder and owns equity of CRA Health (formerly Hughes RiskApps), is co-creator of Ask2Me.Org, which is licensed for commercial use by the Dana-Farber Cancer Institute, and receives honoraria from Myriad Genetics.

\section{References}

1. Legido-Quigley H, Asgari N, Teo YY, Leung GM, Oshitani H, Fukuda K, et al. Are high-performing health systems resilient against the COVID-19 epidemic? The Lancet 2020 Mar;395(10227):848-850. [doi: 10.1016/S0140-6736(20)30551-1]

2. McCall B. COVID-19 and artificial intelligence: protecting health-care workers and curbing the spread. The Lancet Digital Health 2020 Apr;2(4):e166-e167. [doi: 10.1016/s2589-7500(20)30054-6]

3. Niiler E. An AI Epidemiologist Sent the First Alerts of the Coronavirus Internet. Wired. 2020 Jan 25. URL: https://www. wired.com/story/ai-epidemiologist-wuhan-public-health-warnings/ [accessed 2020-07-07]

4. Computational predictions of protein structures associated with COVID-19 Internet. DeepMind. URL: https://deepmind. com/research/open-source/computational-predictions-of-protein-structures-associated-with-COVID-19 [accessed 2020-07-07]

5. Lan L, Xu D, Ye G, Xia C, Wang S, Li Y, et al. Positive RT-PCR test results in patients recovered from COVID-19. JAMA 2020 Apr 21;323(15):1502-1503 [FREE Full text] [doi: 10.1001/jama.2020.2783] [Medline: 32105304]

6. Drew DA, Nguyen LH, Steves CJ, Menni C, Freydin M, Varsavsky T, COPE Consortium. Rapid implementation of mobile technology for real-time epidemiology of COVID-19. Science 2020 Jun 19;368(6497):1362-1367 [FREE Full text] [doi: 10.1126/science.abc0473] [Medline: 32371477]

7. Shaban-Nejad A, Michalowski M, Buckeridge DL. Health intelligence: how artificial intelligence transforms population and personalized health. NPJ Digit Med 2018;1:53 [FREE Full text] [doi: 10.1038/s41746-018-0058-9] [Medline: 31304332]

8. Challen R, Denny J, Pitt M, Gompels L, Edwards T, Tsaneva-Atanasova K. Artificial intelligence, bias and clinical safety. BMJ Qual Saf 2019 Mar;28(3):231-237. [doi: 10.1136/bmjqs-2018-008370] [Medline: $\underline{30636200]}$ 
9. Parikh RB, Teeple S, Navathe AS. Addressing bias in artificial intelligence in health care. JAMA. Epub ahead of print posted online on November 22, 2019 2019. [doi: 10.1001/jama.2019.18058] [Medline: 31755905]

10. Nelson GS. Bias in artificial intelligence. N C Med J 2019;80(4):220-222 [FREE Full text] [doi: $10.18043 / \mathrm{ncm} .80 .4 .220$ ] [Medline: 31278182]

11. Cirillo D, Catuara-Solarz S, Morey C, Guney E, Subirats L, Mellino S, et al. Sex and gender differences and biases in artificial intelligence for biomedicine and healthcare. NPJ Digit Med 2020 Jun 01;3(1):81 [FREE Full text] [doi: 10.1038/s41746-020-0288-5] [Medline: 33597695]

12. Larrazabal AJ, Nieto N, Peterson V, Milone DH, Ferrante E. Gender imbalance in medical imaging datasets produces biased classifiers for computer-aided diagnosis. Proc Natl Acad Sci U S A 2020 Jun 09;117(23):12592-12594 [FREE Full text] [doi: 10.1073/pnas.1919012117] [Medline: 32457147]

13. The impact of sexgender in the COVID-19 pandemic Internet. European Commission. 2020. URL: https://ec.europa.eu/ info/publications/impact-sex-and-gender-covid-19-pandemic en [accessed 2020-07-07]

14. Shilo S, Rossman H, Segal E. Axes of a revolution: challenges and promises of big data in healthcare. Nat Med 2020 Jan;26(1):29-38. [doi: 10.1038/s41591-019-0727-5] [Medline: 31932803]

15. COVID-19 Data Portal. URL: https://www.covid19dataportal.org/ [accessed 2020-10-06]

16. National COVID Cohort Collaborative (N3C) Internet. National Center for Advancing Translational Sciences. URL: https:/ /ncats.nih.gov/n3c [accessed 2020-10-06]

17. The COVID-19 Host Genetics Initiative. COVID-19 hg. URL: https://www.covid19hg.org/ [accessed 2020-10-06]

18. COVID-19 Host Genetics Initiative. The COVID-19 Host Genetics Initiative, a global initiative to elucidate the role of host genetic factors in susceptibility and severity of the SARS-CoV-2 virus pandemic. Eur J Hum Genet 2020 Jun;28(6):715-718 [FREE Full text] [doi: 10.1038/s41431-020-0636-6] [Medline: 32404885]

19. The COVID-19 Sex-Disaggregated Data Tracker. Global Health 50/50 - The Sex, Gender, and COVID-19 Project. URL: https://globalhealth5050.org/the-sex-gender-and-covid-19-project/ [accessed 2020-10-06]

20. Lindvall C, Cassel CK, Pantilat SZ, DeCamp M. Ethical considerations in the use of AI mortality predictions in the care of people with serious illness. Health Affairs. URL: https://www.healthaffairs.org/do/10.1377/hblog20200911.401376/full/ [accessed 2020-10-04]

21. Progress using COVID-19 patient data to train machine learning models for healthcare. University of Cambridge. URL: https://www.cam.ac.uk/research/news/progress-using-covid-19-patient-data-to-train-machine-learning-models-for-healthcare [accessed 2020-07-07]

22. Rahmatizadeh S, Valizadeh-Haghi S, Dabbagh A. The role of artificial intelligence in management of critical COVID-19 patients. Journal of Cellular \& Molecular Anesthesia 2020 Apr;5(1):16-22. [doi: 10.22037/jcma.v5i1.29752]

23. Grasselli G, Pesenti A, Cecconi M. Critical care utilization for the COVID-19 outbreak in Lombardy, Italy: Early experience and forecast during an emergency response. JAMA 2020 Apr 28;323(16):1545-1546. [doi: 10.1001/jama.2020.4031] [Medline: 32167538]

24. Dawson NV, Arkes HR. Systematic errors in medical decision making: judgment limitations. J Gen Intern Med 1987;2(3):183-187. [doi: 10.1007/BF02596149] [Medline: $\underline{\text { 3295150] }}$

25. Sendak MP, Ratliff W, Sarro D, Alderton E, Futoma J, Gao M, et al. Real-world integration of a sepsis deep learning technology into routine clinical care: implementation study. JMIR Med Inform 2020 Jul 15;8(7):e15182 [FREE Full text] [doi: 10.2196/15182] [Medline: 32673244]

26. Verghese A, Shah NH, Harrington RA. What this computer needs is a physician: humanism and artificial intelligence. JAMA 2018 Jan 02;319(1):19-20. [doi: 10.1001/jama.2017.19198] [Medline: 29261830]

27. Patel BN, Rosenberg L, Willcox G, Baltaxe D, Lyons M, Irvin J, et al. Human-machine partnership with artificial intelligence for chest radiograph diagnosis. NPJ Digit Med 2019;2:111 [FREE Full text] [doi: 10.1038/s41746-019-0189-7] [Medline: 31754637]

28. Vindegaard N, Benros ME. COVID-19 pandemic and mental health consequences: systematic review of the current evidence. Brain Behav Immun 2020 Oct;89:531-542 [FREE Full text] [doi: 10.1016/j.bbi.2020.05.048] [Medline: 32485289]

29. Figueroa CA, Aguilera A. The need for a mental health technology revolution in the COVID-19 pandemic. Front Psychiatry 2020;11:523 [FREE Full text] [doi: 10.3389/fpsyt.2020.00523] [Medline: 32581891]

30. Topol EJ. High-performance medicine: the convergence of human and artificial intelligence. Nat Med 2019 Jan;25(1):44-56. [doi: 10.1038/s41591-018-0300-7] [Medline: 30617339]

31. Panch T, Mattie H, Celi LA. The "inconvenient truth" about AI in healthcare. NPJ Digit Med 2019;2:77 [FREE Full text] [doi: 10.1038/s41746-019-0155-4] [Medline: 31453372]

32. Lin SY, Mahoney MR, Sinsky CA. Ten ways artificial intelligence will transform primary care. J Gen Intern Med 2019 Aug;34(8):1626-1630 [FREE Full text] [doi: 10.1007/s11606-019-05035-1] [Medline: 31090027]

33. Liu X, Cruz Rivera S, Moher D, Calvert MJ, Denniston AK, SPIRIT-AICONSORT-AI Working Group. Reporting guidelines for clinical trial reports for interventions involving artificial intelligence: the CONSORT-AI extension. Nat Med 2020 Sep;26(9):1364-1374 [FREE Full text] [doi: 10.1038/s41591-020-1034-x] [Medline: 32908283]

34. Cruz Rivera S, Liu X, Chan A, Denniston A, Calvert M, SPIRIT-AICONSORT-AI Working Group, SPIRIT-AICONSORT-AI Steering Group, SPIRIT-AICONSORT-AI Consensus Group. Guidelines for clinical trial protocols for interventions 
involving artificial intelligence: the SPIRIT-AI extension. Nat Med 2020 Sep;26(9):1351-1363 [FREE Full text] [doi: 10.1038/s41591-020-1037-7] [Medline: 32908284]

35. Filipp FV. Opportunities for artificial intelligence in advancing precision medicine. Curr Genet Med Rep 2019 Dec;7(4):208-213 [FREE Full text] [doi: 10.1007/s40142-019-00177-4] [Medline: 31871830]

36. Zeggini E, Gloyn AL, Barton AC, Wain LV. Translational genomics and precision medicine: moving from the lab to the clinic. Science 2019 Sep 27;365(6460):1409-1413. [doi: 10.1126/science.aax4588] [Medline: $\underline{31604268]}$

37. Gruson D, Helleputte T, Rousseau P, Gruson D. Data science, artificial intelligence, and machine learning: opportunities for laboratory medicine and the value of positive regulation. Clin Biochem 2019 Jul;69:1-7. [doi: 10.1016/j.clinbiochem.2019.04.013] [Medline: 31022391]

38. Suspected COVID-19 pneumonia Diagnosis Aid System. URL: https://intensivecare.shinyapps.io/COVID19/ [accessed 2021-02-19]

39. Feng C, Huang Z, Wang L, Chen X, Zhai Y, Zhu F, et al. A novel triage tool of artificial intelligence assisted diagnosis aid system for suspected COVID-19 pneumonia in fever clinics. medRxiv. Preprint posted online on March 20, 2020. [doi: $\underline{10.1101 / 2020.03 .19 .20039099]}$

40. Jiang X, Coffee M, Bari A, Wang J, Jiang X, Huang J, et al. Towards an artificial intelligence framework for data-driven prediction of coronavirus clinical severity. Computers, Materials \& Continua 2020 Mar;63(1):537-551 [FREE Full text] [doi: $10.32604 / \mathrm{cmc} .2020 .010691$ ]

41. Freedman AN, Seminara D, Gail MH, Hartge P, Colditz GA, Ballard-Barbash R, et al. Cancer risk prediction models: a workshop on development, evaluation, and application. J Natl Cancer Inst 2005 May 18;97(10):715-723. [doi: 10.1093/jnci/dji128] [Medline: 15900041]

42. Yala A, Lehman C, Schuster T, Portnoi T, Barzilay R. A deep learning mammography-based model for improved breast cancer risk prediction. Radiology 2019 Jul;292(1):60-66. [doi: 10.1148/radiol.2019182716] [Medline: 31063083]

43. Hu S, Santus E, Forsyth AW, Malhotra D, Haimson J, Chatterjee NA, et al. Can machine learning improve patient selection for cardiac resynchronization therapy? PLoS One 2019;14(10):e0222397 [FREE Full text] [doi: 10.1371/journal.pone.0222397] [Medline: 31581234]

44. Wynants L, Van Calster B, Collins GS, Riley RD, Heinze G, Schuit E, et al. Prediction models for diagnosis and prognosis of covid-19 infection: systematic review and critical appraisal. BMJ 2020 Apr 07;369:m1328 [FREE Full text] [doi: 10.1136/bmj.m1328] [Medline: 32265220]

45. Mei X, Lee H, Diao K, Huang M, Lin B, Liu C, et al. Artificial intelligence-enabled rapid diagnosis of patients with COVID-19. Nat Med 2020 Aug;26(8):1224-1228 [FREE Full text] [doi: 10.1038/s41591-020-0931-3] [Medline: 32427924]

46. Jin C, Chen W, Cao Y, Xu Z, Zhang X, Deng L, et al. Development and Evaluation of an AI System for COVID-19 Diagnosis. medRxiv. Preprint posted online on June 02, 2020. [doi: 10.1101/2020.03.20.20039834]

47. Schaffter T, Buist DSM, Lee CI, Nikulin Y, Ribli D, Guan Y, the DM DREAM Consortium, et al. Evaluation of combined artificial intelligence and radiologist assessment to interpret screening mammograms. JAMA Netw Open 2020 Mar 02;3(3):e200265 [FREE Full text] [doi: 10.1001/jamanetworkopen.2020.0265] [Medline: 32119094]

48. Xiao L, Li P, Sun F, Zhang Y, Xu C, Zhu H, et al. Development and validation of a deep learning-based model using computed tomography imaging for predicting disease severity of coronavirus disease 2019. Front Bioeng Biotechnol 2020;8:898 [FREE Full text] [doi: 10.3389/fbioe.2020.00898] [Medline: 32850746]

49. Clinical management of severe acute respiratory infection (SARI) when COVID-19 disease is suspected. World Health Organization. 2020 Mar 13. URL: https://www.who.int/docs/default-source/coronaviruse/clinical-management-of-novel-cov. pdf?sfvrsn=bc7da517 2 [accessed 2021-02-19]

50. NIH harnesses AI for COVID-19 diagnosis, treatment, and monitoring. National Institutes of Health. 2020 Aug 05. URL: https://www.nih.gov/news-events/news-releases/nih-harnesses-ai-covid-19-diagnosis-treatment-monitoring [accessed 2020-10-06]

51. Yan L, Zhang H, Goncalves J, Xiao Y, Wang M, Guo Y, et al. A machine learning-based model for survival prediction in patients with severe COVID-19 infection. medRxiv. Preprint posted online on March 17, 2020. [FREE Full text] [doi: $\underline{10.1101 / 2020.02 .27 .20028027]}$

52. Senanayake SL. Drug repurposing strategies for COVID-19. Future Drug Discovery 2020 Apr 01;2(2) [FREE Full text] [doi: 10.4155/fdd-2020-0010]

53. Zhavoronkov A, Aladinskiy V, Zhebrak A, Zagribelnyy B, Terentiev V, Bezrukov D, et al. Potential COVID-2019 3C-like Protease Inhibitors Designed Using Generative Deep Learning Approaches. ChemRxiv. Preprint posted online on February 11, 2020. [FREE Full text]

54. Gordon DE, Jang GM, Bouhaddou M, Xu J, Obernier K, White KM, et al. A SARS-CoV-2 protein interaction map reveals targets for drug repurposing. Nature 2020 Jul;583(7816):459-468 [FREE Full text] [doi: 10.1038/s41586-020-2286-9] [Medline: 32353859]

55. Richardson P, Griffin I, Tucker C, Smith D, Oechsle O, Phelan A, et al. Baricitinib as potential treatment for 2019-nCoV acute respiratory disease. The Lancet 2020 Feb;395(10223):e30-e31. [doi: 10.1016/s0140-6736(20)30304-4] 
56. Beck BR, Shin B, Choi Y, Park S, Kang K. Predicting commercially available antiviral drugs that may act on the novel coronavirus (SARS-CoV-2) through a drug-target interaction deep learning model. Comput Struct Biotechnol J 2020;18:784-790 [FREE Full text] [doi: 10.1016/j.csbj.2020.03.025] [Medline: $\underline{32280433}$ ]

57. Ostaszewski M, Mazein A, Gillespie ME, Kuperstein I, Niarakis A, Hermjakob H, et al. COVID-19 disease map, building a computational repository of SARS-CoV-2 virus-host interaction mechanisms. Sci Data 2020 May 05;7(1):136 [FREE Full text] [doi: 10.1038/s41597-020-0477-8] [Medline: $\underline{\text { 32371892] }}$

58. Gysi D, Valle ID, Zitnik M, Ameli A, Gan X, Varol O, et al. Network medicine framework for identifying drug repurposing opportunities for COVID-19. arXiv. Preprint posted online on April 15, 2020. [FREE Full text]

59. Fleming N. How artificial intelligence is changing drug discovery. Nature 2018 May;557(7707):S55-S57. [doi: 10.1038/d41586-018-05267-x] [Medline: 29849160]

60. Stokes JM, Yang K, Swanson K, Jin W, Cubillos-Ruiz A, Donghia NM, et al. A deep learning approach to antibiotic discovery. Cell 2020 Feb 20;180(4):688-702.e13. [doi: 10.1016/j.cell.2020.01.021] [Medline: $\underline{32084340]}$

61. Senior AW, Evans R, Jumper J, Kirkpatrick J, Sifre L, Green T, et al. Improved protein structure prediction using potentials from deep learning. Nature 2020 Jan;577(7792):706-710. [doi: 10.1038/s41586-019-1923-7] [Medline: 31942072]

62. Nelson MR, Johnson T, Warren L, Hughes AR, Chissoe SL, Xu C, et al. The genetics of drug efficacy: opportunities and challenges. Nat Rev Genet 2016 Apr;17(4):197-206. [doi: 10.1038/nrg.2016.12] [Medline: 26972588]

63. Tan-Koi WC, Leow PC, Teo YY. Applications of pharmacogenomics in regulatory science: a product life cycle review. Pharmacogenomics J 2018 May 22;18(3):359-366. [doi: 10.1038/tpj.2017.47] [Medline: 29205206]

64. Weinshilboum RM, Wang L. Pharmacogenomics: precision medicine and drug response. Mayo Clin Proc 2017 Nov;92(11):1711-1722 [FREE Full text] [doi: 10.1016/j.mayocp.2017.09.001] [Medline: 29101939]

65. Lauschke VM, Ingelman-Sundberg M. Emerging strategies to bridge the gap between pharmacogenomic research and its clinical implementation. NPJ Genom Med 2020 Mar 05;5(1):9 [FREE Full text] [doi: 10.1038/s41525-020-0119-2] [Medline: 33579994]

66. Silverman EK. Genetics of COPD. Annu Rev Physiol 2020 Feb 10;82:413-431 [FREE Full text] [doi: 10.1146/annurev-physiol-021317-121224] [Medline: 31730394$]$

67. Severe acute respiratory syndrome coronavirus 2 isolate Wuhan-Hu-1, complete genome. NCBI. URL: https://www. ncbi.nlm.nih.gov/nuccore/MN908947 [accessed 2020-10-04]

68. Real-time tracking of pathogen evolution - SARS-CoV-2 (COVID-19). Nextstrain. URL: https://nextstrain.org/ [accessed 2021-02-22]

69. Kachuri L, Francis S, Morrison M, Wendt GA, Bossé Y, Cavazos TB, et al. The landscape of host genetic factors involved in immune response to common viral infections. Genome Med 2020 Oct 27;12(1):93 [FREE Full text] [doi: 10.1186/s13073-020-00790-x] [Medline: 33109261]

70. Benetti E, Tita R, Spiga O, Ciolfi A, Birolo G, Bruselles A, GEN-COVID Multicenter Study, et al. ACE2 gene variants may underlie interindividual variability and susceptibility to COVID-19 in the Italian population. Eur J Hum Genet 2020 Nov;28(11):1602-1614 [FREE Full text] [doi: 10.1038/s41431-020-0691-z] [Medline: $\underline{32681121]}$

71. Takahashi T, Luzum JA, Nicol MR, Jacobson PA. Pharmacogenomics of COVID-19 therapies. NPJ Genom Med 2020;5:35 [FREE Full text] [doi: 10.1038/s41525-020-00143-y] [Medline: 32864162]

72. Wenham C, Smith J, Morgan R. COVID-19: the gendered impacts of the outbreak. The Lancet 2020 Mar;395(10227):846-848. [doi: 10.1016/s0140-6736(20)30526-2]

73. Nelson MR, Tipney H, Painter JL, Shen J, Nicoletti P, Shen Y, et al. The support of human genetic evidence for approved drug indications. Nat Genet 2015 Aug;47(8):856-860. [doi: 10.1038/ng.3314] [Medline: 26121088]

74. Dugger SA, Platt A, Goldstein DB. Drug development in the era of precision medicine. Nat Rev Drug Discov 2018 Mar;17(3):183-196 [FREE Full text] [doi: 10.1038/nrd.2017.226] [Medline: 29217837]

75. Severe Covid-19 GWAS Group, Ellinghaus D, Degenhardt F, Bujanda L, Buti M, Albillos A, et al. Genomewide association study of severe Covid-19 with respiratory failure. N Engl J Med 2020 Oct 15;383(16):1522-1534 [FREE Full text] [doi: 10.1056/NEJMoa2020283] [Medline: 32558485]

76. Ton A, Gentile F, Hsing M, Ban F, Cherkasov A. Rapid identification of potential inhibitors of SARS-CoV-2 main protease by deep docking of 1.3 billion compounds. Mol Inform 2020 Aug;39(8):e2000028 [FREE Full text] [doi: 10.1002/minf.202000028] [Medline: 32162456]

77. Abbasi B, Saraf D, Sharma T, Sinha R, Singh S, Gupta P, et al. OSF Preprints. Preprint posted online April 08, 2020. [doi: 10.31219/osf.io/f8zyw]

78. Ong E, Wang H, Wong MU, Seetharaman M, Valdez N, He Y. Vaxign-ML: supervised machine learning reverse vaccinology model for improved prediction of bacterial protective antigens. Bioinformatics 2020 May 01;36(10):3185-3191. [doi: 10.1093/bioinformatics/btaa119] [Medline: 32096826]

79. Malone B, Simovski B, Moliné C, Cheng J, Gheorghe M, Fontenelle H, et al. Artificial intelligence predicts the immunogenic landscape of SARS-CoV-2: toward universal blueprints for vaccine designs. bioRxiv. Preprint posted online on April 21, 2020. [FREE Full text] [doi: 10.1101/2020.04.21.052084]

80. Keshavarzi Arshadi A, Webb J, Salem M, Cruz E, Calad-Thomson S, Ghadirian N, et al. Artificial intelligence for COVID-19 drug discovery and vaccine development. Front Artif Intell 2020 Aug 18;3. [doi: 10.3389/frai.2020.00065] 
81. Hoffmann M, Kleine-Weber H, Schroeder S, Krüger N, Herrler T, Erichsen S, et al. SARS-CoV-2 cell entry depends on ACE2 and TMPRSS2 and is blocked by a clinically proven protease inhibitor. Cell 2020 Apr 16;181(2):271-280.e8 [FREE Full text] [doi: 10.1016/j.cell.2020.02.052] [Medline: 32142651]

82. Santus E, Li C, Yala A, Peck D, Soomro R, Faridi N, et al. Do neural information extraction algorithms generalize across institutions? JCO Clin Cancer Inform 2019 Jul;3:1-8 [FREE Full text] [doi: 10.1200/CCI.18.00160] [Medline: 31310566$]$

83. Santus E, Schuster T, Tahmasebi AM, Li C, Yala A, Lanahan CR, et al. Exploiting rules to enhance machine learning in extracting information from multi-institutional prostate pathology reports. JCO Clin Cancer Inform 2020 Oct;4:865-874 [FREE Full text] [doi: 10.1200/CCI.20.00028] [Medline: 33006906]

84. Adnan K, Akbar R. An analytical study of information extraction from unstructured and multidimensional big data. J Big Data 2019 Oct 17;6:91. [doi: 10.1186/s40537-019-0254-8]

85. Domingo-Fernández D, Baksi S, Schultz B, Gadiya Y, Karki R, Raschka T, et al. COVID-19 Knowledge Graph: a computable, multi-modal, cause-and-effect knowledge model of COVID-19 pathophysiology. bioRxiv. Preprint posted online on April 15, 2020. [doi: 10.1101/2020.04.14.040667]

86. Cowen L, Ideker T, Raphael BJ, Sharan R. Network propagation: a universal amplifier of genetic associations. Nat Rev Genet 2017 Sep;18(9):551-562. [doi: 10.1038/nrg.2017.38] [Medline: 28607512]

87. Humayun F, Domingo-Fernández D, Paul George AA, Hopp M, Syllwasschy BF, Detzel MS, et al. A computational approach for mapping heme biology in the context of hemolytic disorders. Front Bioeng Biotechnol 2020;8:74 [FREE Full text] [doi: 10.3389/fbioe.2020.00074] [Medline: 32211383]

88. Nelson W, Zitnik M, Wang B, Leskovec J, Goldenberg A, Sharan R. To embed or not: network embedding as a paradigm in computational biology. Front Genet 2019;10:381 [FREE Full text] [doi: 10.3389/fgene.2019.00381] [Medline: 31118945]

89. Hamilton WL, Ying R, Leskovec J. Representation learning on graphs: methods and applications. IEEE Data Engineering Bulletin 2017;40(3):52-74 [FREE Full text]

90. KG-Covid-19 Knowledge Graph Hub. GitHub. URL: https://github.com/Knowledge-Graph-Hub/kg-covid-19 [accessed 2021-02-22]

91. COVID-19 Community Project. GitHub. URL: https://github.com/covid-19-net/covid-19-community [accessed 2021-02-22]

92. COVID-KG. GitHub. URL: https://github.com/GillesVandewiele/COVID-KG/ [accessed 2021-02-22]

93. COVID-19 Knowledge Graph. CovidGraph. URL: https://covidgraph.org/ [accessed 2021-02-22]

94. COVID-19 Miner. GitHub. URL: https://github.com/rupertoverall/covid19-miner [accessed 2021-02-22]

95. COVID-19 Biomedical Knowledge Miner. Biomedical Knowledge Miner (BiK>Mi). URL: https://bikmi. covid19-knowledgespace.de/ [accessed 2021-02-22]

96. COVID-19 Taxila. URL: http://covid19.taxila.io/ [accessed 2021-02-22]

97. COVID-19 Open Research Dataset Challenge (CORD-19). Kaggle (Allen Institute For AI). URL: https://www.kaggle.com/ allen-institute-for-ai/CORD-19-research-challenge [accessed 2020-10-04]

98. The COVID-19 Drug and Gene Set Library. Ma'ayan Laboratory, Computational Systems Biology. URL: https://amp. pharm.mssm.edu/covid19/ [accessed 2021-02-22]

99. Ristoski P, Rosati J, Di Noia T, De Leone R, Paulheim H. RDF2Vec: RDF graph embeddings and their applications. SW 2019 May 23;10(4):721-752. [doi: 10.3233/sw-180317]

100. COVID-19 SARS-CoV-2 preprints from medRxiv and bioRxiv. URL: https://connect.biorxiv.org/relate/content/181 [accessed 2020-10-04]

101. The Lancet Public Health. COVID-19 puts societies to the test. The Lancet Public Health 2020 May;5(5):e235. [doi: 10.1016/s2468-2667(20)30097-9]

102. Alam F, Dalvi F, Shaar S, Durrani N, Mubarak H, Nikolov A, et al. Fighting the COVID-19 infodemic in social media: a holistic perspective and a call to arms. arXiv. Preprint posted online on July 15, 2020 [FREE Full text]

103. Song X, Petrak J, Jiang Y, Singh I, Maynard D, Bontcheva K. Classification aware neural topic model and its application on a new COVID-19 disinformation corpus. arXiv. Preprint posted online on June 5, 2020 [FREE Full text]

104. Li Y, Grandison T, Silveyra P, Douraghy A, Guan X, Kieselbach T, et al. Jennifer for COVID-19: An NLP-powered chatbot built for the people and by the people to combat misinformation. : Association for Computational Linguistics; 2020 Presented at: Proceedings of the 1st Workshop on NLP for COVID-19 at ACL 2020; July 2020; Online URL: https://www.aclweb.org/ anthology/2020.nlpcovid19-acl.9

105. The COVID-19 High Performance Computing Consortium. URL: https://covid19-hpc-consortium.org/ [accessed 2021-02-22]

106. Fogel AL, Kvedar JC. Artificial intelligence powers digital medicine. NPJ Digit Med 2018;1:5 [FREE Full text] [doi: 10.1038/s41746-017-0012-2] [Medline: 31304291]

107. Shen B, Yi X, Sun Y, Bi X, Du J, Zhang C, et al. Proteomic and metabolomic characterization of COVID-19 patient sera. Cell 2020 Jul 09;182(1):59-72.e15 [FREE Full text] [doi: 10.1016/j.cell.2020.05.032] [Medline: $\underline{32492406}$ ]

108. Ahmed Z, Mohamed K, Zeeshan S, Dong X. Artificial intelligence with multi-functional machine learning platform development for better healthcare and precision medicine. Database (Oxford) 2020 Jan 01;2020:baaa010 [FREE Full text] [doi: 10.1093/database/baaa010] [Medline: $\underline{32185396]}$ 
109. Shah P, Kendall F, Khozin S, Goosen R, Hu J, Laramie J, et al. Artificial intelligence and machine learning in clinical development: a translational perspective. NPJ Digit Med 2019;2:69 [FREE Full text] [doi: 10.1038/s41746-019-0148-3] [Medline: $\underline{31372505]}$

110. Mahalle P, Sable N, Mahalle N, Shinde G. Data analytics: COVID-19 prediction using multimodal data. Preprints. Preprint published online on April 16, 2020. [doi: 10.20944/preprints202004.0257.v2]

111. Overmyer KA, Shishkova E, Miller IJ, Balnis J, Bernstein MN, Peters-Clarke TM, et al. Large-scale multi-omic analysis of COVID-19 severity. medRxiv. Preprint posted online on July 19, 2020 [FREE Full text] [doi: 10.1101/2020.07.17.20156513] [Medline: $\underline{\text { 32743614] }}$

112. Ray S, Srivastava S. COVID-19 pandemic: hopes from proteomics and multiomics research. OMICS 2020 Aug;24(8):457-459. [doi: 10.1089/omi.2020.0073] [Medline: 32427517]

113. Schork N. Artificial intelligence and personalized medicine. In: Von Hoff D, Han H, editors. Precision Medicine in Cancer Therapy. Cancer Treatment and Research. Cham: Springer; 2019:265-283.

114. The Cost of Sequencing a Human Genome. National Human Genome Research Institute. URL: https://www.genome.gov/ about-genomics/fact-sheets/Sequencing-Human-Genome-cost [accessed 2020-10-06]

115. Dias R, Torkamani A. Artificial intelligence in clinical and genomic diagnostics. Genome Med 2019 Nov 19;11(1):70 [FREE Full text] [doi: 10.1186/s13073-019-0689-8] [Medline: 31744524]

116. Kelly CJ, Karthikesalingam A, Suleyman M, Corrado G, King D. Key challenges for delivering clinical impact with artificial intelligence. BMC Med 2019 Oct 29;17(1):195. [doi: 10.1186/s12916-019-1426-2] [Medline: 31665002]

\title{
Abbreviations
}

ACE2: angiotensin-converting enzyme 2

AI: artificial intelligence

AUROC: area under the receiver operating characteristic curve

CNN: convolutional neural network

CONSORT-AI: Consolidated Standards of Reporting Trials-Artificial Intelligence

CT: computed tomography

FDA: Food and Drug Administration

GWAS: genome-wide association studies

HLA: human leukocyte antigen

ICU: intensive care unit

KG: knowledge graph

LASSO: least absolute shrinkage and selection operator

NLP: natural language processing

SPIRIT-AI: Standard Protocol Items: Recommendations for Interventional Trials-Artificial Intelligence

\author{
Edited by G Eysenbach, C Basch; submitted 12.07.20; peer-reviewed by K Ferrini, M Afzal; comments to author 17.08.20; revised \\ version received 07.10.20; accepted 31.01.21; published 12.03.21 \\ Please cite as: \\ Santus E, Marino N, Cirillo D, Chersoni E, Montagud A, Santuccione Chadha A, Valencia A, Hughes K, Lindvall C \\ Artificial Intelligence-Aided Precision Medicine for COVID-19: Strategic Areas of Research and Development \\ $J$ Med Internet Res 2021;23(3):e22453 \\ URL: https://www.jmir.org/2021/3/e22453 \\ doi: $\underline{10.2196 / 22453}$ \\ PMID: 33560998
}

CEnrico Santus, Nicola Marino, Davide Cirillo, Emmanuele Chersoni, Arnau Montagud, Antonella Santuccione Chadha, Alfonso Valencia, Kevin Hughes, Charlotta Lindvall. Originally published in the Journal of Medical Internet Research (http://www.jmir.org), 12.03.2021. This is an open-access article distributed under the terms of the Creative Commons Attribution License (https://creativecommons.org/licenses/by/4.0/), which permits unrestricted use, distribution, and reproduction in any medium, provided the original work, first published in the Journal of Medical Internet Research, is properly cited. The complete bibliographic information, a link to the original publication on http://www.jmir.org/, as well as this copyright and license information must be included. 